\title{
Quality of Water and the Recovery Time of Malnourished Children Enrolled In a Nutritional Feeding Programme: Lessons from Parkishon Region, Marsabit County, Kenya
}

\author{
Peter G. Kirira ${ }^{1 *}$, Connie Cheren ${ }^{2}$, Linus Ndegwa ${ }^{2}$, Ashley Waudo ${ }^{2}$ \\ ${ }^{1}$ Directorate of Research, Grants and Endowment, Mount Kenya University, Thika, Kenya \\ ${ }^{2}$ Partners for Care, Geoffrey Lurutti Road, Nairobi, Kenya
}

*Corresponding Author: Dr. Peter G. Kirira, Directorate of Research, Grants and Endowment, Mount Kenya University, P.O. Box 342-01000, Thika, Kenya, E-mail: peterkirira@gmail.com

Received: 06 July 2018; Accepted: 12 July 2018; Published: 22 July 2018

\begin{abstract}
Objective: Malnutrition is a problem that continues to plague children from resource scarce regions of Kenya. To address this health challenge, the government of Kenya initiated feeding programmes aimed at improving the daily nutritional food intake of underweight and sickly children from these regions. This study examined the relationship between the quality of water and the children's recovery as measured by the Mid-Upper Arm Circumference (MUAC) in Parkishon region of Kenya.
\end{abstract}

Methods: The study followed 82 underweight children on a PlumpNut diet. Thirty seven (37) children were using water from a water backpack while the other children were using water from Silanga, a dam that is the only source of water in the region. The recovery time of the children was measured using the MUAC index.

Results: Of the 37 children enrolled in the nutritional feeding programme and from families that received the water backpack, 10 recovered fully within three months and were put off the nutritional supplement program. The underweight children in the same nutritional feeding programme but whose families did not receive the water backpack, and therefore continued to consume water from the dam, are yet to recover and are still enrolled in the nutritional feeding programme. 
Conclusion: The study showed that the children nutritional feeding programmes should put into consideration the quality of water since it affects the recovery time of children enrolled in the nutritional programme. This study demonstrated the significant role of the water backpack in improving the health conditions of the children.

Keywords: Parkishon; Malnourished children; Nutritional programme; PlumpyNut; Water backpack

\section{Introduction}

Malnutrition affects physical growth, morbidity, mortality, cognitive development, reproduction, and physical work capacity, and it consequently impacts on human performance, health and survival. Malnutrition is a global public health problem, whose factors that contribute to it are many and varied. These include unsatisfactory food intake, repeated infections, maternal and childcare, healthcare and availability of safe water. Drinking untreated water is often a source of disease because it can contain pathogens as well as chemical agents. Inadequate sanitary conditions lead to the death of 1.5 million children each year worldwide, with $88 \%$ of these deaths due to diarrhea [1]. Diarrhea is often linked to availability of clean safe water.

The study was carried out in Parkishon, located in Karare location, Central division, Saku Constituency in Marsabit County, Northern Kenya. It is a water scarce region and therefore does not have adequate agricultural yields. Among the issues plaguing Parkishon include poor nutrition and lack of safe water where about $14.4 \%$ of the children are at risk of malnutrition. In an effort to address this issue the Kenyan government since March 2014, has embarked on a feeding programme to boost nutrition among children in this area. The children are fed on Plumpy'Nut, a highenergy peanut-based paste that includes skimmed milk powder, sugar, vegetable fat and vitamins and minerals, which is known to solve cases of malnutrition. It has however been observed that the children on this diet have remained malnourished. A possible cause of this is that the children are still consuming contaminated water which leads to waterborne illnesses therefore counteracting gains from the government sponsored nutritional supplements. Access to safe water in Parkishon area is difficult as the water sources are scarce, and highly contaminated. Residents in the area have to make do with the contaminated water available from a dam, popularly known as "silanga" in Rendille. The water is used for both domestic purposes, including drinking, cooking and washing, and for their animals to drink and wash. Sanitation in the area is also inadequate as open defecation is quite high despite having toilet facilities in the area. This practice exposes the water source to further contamination, especially during the rains when the surface water is washed to the watering points.

In collaboration with the County Government of Marsabit, Partners for Care a local NGO whose mission is to decrease the number of children dying from preventable diseases, procured and donated water backpacks to the residents of Parkishon, trained Community Health Workers (CHWs), and assisted with implementation of a safe water project. The households were chosen from the geographic area for the study because of lack of safe water and the presence of malnourished children despite Government efforts to place them in the feeding program. The children are easily monitored in the Parkishon dispensary, a Ministry of Health dispensary. There are approximately 
380 households in Parkishon with an average population of six per household. Rationale for the selection of this area includes the following factors:

1. Ethnic Diversity - It is understood that people from multiple ethnic groups live within Parkishon area.

2. Partners for Care (PFC)- PFC have established relationships in Parkishon as they have staff located in Marsabit not far from the study site who ensure proper water and sanitation practices are carried out in Parkishon.

3. Parkishon dispensary -It serves to monitor the childrens' conditions and tracks their health status.

4. Community Health Volunteers (CHVs) - The presence of well-trained CHVs equipped with bicycles by PFC for mobility ensures there is true behaviour change in the community with regards to safe water and sanitation as they closely monitor the population.

5. Less impact of Plumpy'Nut - In March 2014, the Kenyan Government began issuing Plumpy'Nut to the residents of Marsabit. This activity was done in response to drought in several parts of the country, Marsabit being one of the counties as it is a water scarce region. However, the nutrition situation has not changed much as some children in the area remain malnourished.

6. Contaminated Water Source - The residents of Parkishon have one common water source, a dam (Silanga). The residents are prone to waterborne illnesses due to consumption of the contaminated water from this water source.

Through their sensitization, locals became more aware that lack of safe water is a major impediment to proper growth of the children. This study was carried out to demonstrate whether use of safe water would influence the recovery period of malnourished children under the government sponsored PlumpyNut nutritional programme. This evaluation is anticipated to lead to practical, evidence-based guidance for potential implementation countrywide. This study therefore evaluated the benefits of safe water provision through water backpacks to the health and nutrition status of the children of Parkishon community

\section{Methodology}

\subsection{Study site}

Parkishon is in Saku Constituency, Karare Location, $15 \mathrm{~km}$ from Marsabit town in Northern Kenya. It is culturally heterogeneous (95\% Samburu and Rendille tribe) and has a projected population of 59,560 (KNBS) [2].

\subsection{Study population}

2.2.1 Inclusion Criteria: All children under the age of five from the households within the defined study area and receiving the Plumpy'Nut supplement were eligible for enrollment in the study.

2.2.2 Exclusion criteria: All children from other areas and whose parents did not consent were excluded from the study. 


\subsection{Intervention}

Nutrition programs have been implemented consistently in Parkishon village, about 30 miles outside of Marsabit County, Kenya, over the past two years and will continue as part of the Government program for the coming years. Thus this area was ideally suited for the water backpack (pack $\mathrm{H}_{2} \mathrm{O}$ ) implementation project because a key evaluation metric (observed cases of diarrhea, dysentery and monitoring of growth among the children of Parkishon) have been collected throughout pre-intervention, intervention, and post-intervention periods.

Plumpy'Nut is known to solve the problem of hunger and malnutrition but in this case the children in Parkishon have been fed on Plumpy'Nut supplements but have remained malnourished. A possible cause of this is that the children were consuming contaminated water, therefore counteracting Government efforts. Training in safe practices of water treatment, safe water storage and hygiene is important. Water availability and quality are still challenges in developing countries, including Kenya. Women, often responsible for fetching household water, sometimes have to trek long distances to find water and even then the quality of the water is suspect. Safe water can reduce water related deaths by $21 \%$ (United Nations Millennium Project. Health, Dignity and Development) [3]. Water packs (pack $\mathrm{H}_{2} \mathrm{O}$ ) is an innovative tool developed and manufactured by Greif, Inc. Over the past two years Partners for Care has distributed the water backpacks to both rural and urban communities in Kenya. The water backpack replaces contaminated, heavy bucket and jerry cans commonly used by women fetching water and provides an easy, clean, safe way to transport and store water. The water backpacks ensure that the most impoverished and malnourished children of Parkishon have access to safe water.

\subsection{Intervention steps}

- Partners for Care (PFC) trained four Community Health Volunteers (CHVs) on how to use the water backpacks and maintain supply of clean safe water. This is a two-step process-using Pure to remove the mud and debris, filtering the water through a cloth into the pack $\mathrm{H}_{2} \mathrm{O}$ water backpack and then using water guard. PFC is partnering with the Marsabit County Government who provide the Pure and the water guard.

- PFC supplied water backpacks to the 380 Households (HHs); each HH received two water backpacks. Individuals tasked with the responsibility of fetching water are provided with Pure and water guard at Parkishon dispensary anytime they need to treat water before it is consumed.

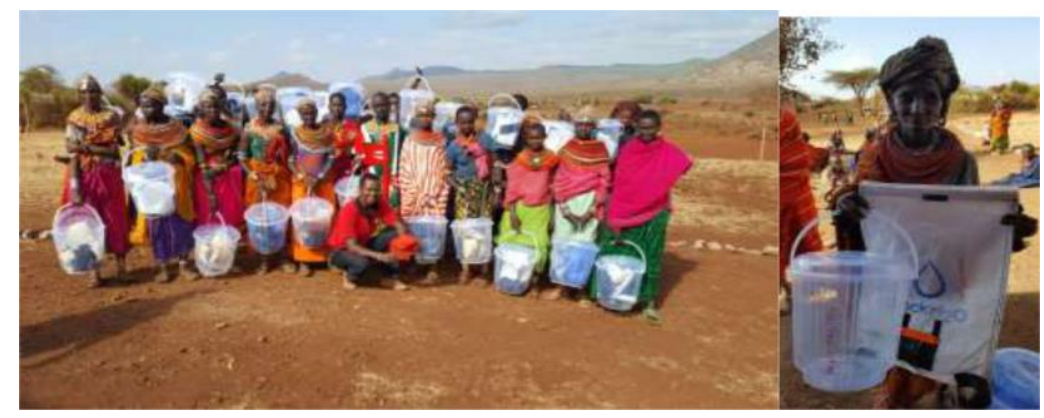

Image 1: Pure and water guard at Parkishon dispensary anytime they need to treat water before it is consumed. 
Women from Parkishon after receiving water backpack and buckets from PFC. The woman in the photo (right) said that she has had waterborne illnesses all her life and she is glad she can now take safe water for the remaining years of her life

- Each household was provided with a bar of soap and a soap container. This is because five washing stations were set up at strategic locations near the targeted households and the water backpack served to dispense hand washing water. This is to ensure households practice proper sanitation.

- Nine water backpacks were issued in every classroom at Parkishon Primary to ensure that the children have access to safe water both at home and at school.

2.5 Study design for assessing intervention impact

2.5.1 Procedure for Clinic visits: Selected children for the study visited Parkishon dispensary on a weekly basis. The children from the study had a standardized observation tool completed during every visit by the clinician. This tool measured the children' weight, height and Mid-Upper Arm Circumference (MUAC) throughout the three month study period.

2.5.2 Procedure for household visits: PFC trained four Community Health volunteers on proper use of the water backpack and maintenance of safe water practices before the study. The Community Health Volunteers were given the responsibility of ensuring the residents use the water backpacks correctly and maintain safe water practices. They visited the homes regularly to verify correct use and addressed challenges with regard to the incorrect use of the water backpack.

PFC staff visited each participating household in the study area bi-weekly to ensure proper use of the water backpacks and maintenance of safe water practices. Household members were defined as those using a common water site. Prior to the implementing surveillance activities in Parkishon, PFC met with the relevant authorities in order to inform them of the proposed activities for their approval.

\subsection{Limitations}

The existence of malnourished children in Parkishon who are on Plumpy'Nut but rarely drink safe water proved to be a liability to the effectiveness of the study. This is because they experienced recurrent diarrhea hence there is no improvement in their health status. According to Mr. Adan Galoro, a clinician at Parkishon dispensary, once the children MUAC measurements improves (>12.4) and experience no diarrheal infection, within two months, they are off Plumpy'Nut. When there is Plumpy'Nut and recurrent infection, the process is slowed down to 6-12 months.

Open defecation is a major issue in Parkishon that pollutes the water source. Their cultural beliefs/norms are major contributors to this habit; men and women do not share latrines, the locals believe sharing a latrine shortens once lifespan and they don't like the smell that emanates from them. These beliefs discourage the use of the latrines that 
have been built by the Ministry of Public Health. Despite these, the Ministry of Public Health is relentless at offering training on proper hygiene and sanitation to the resident of Parkishon.

Efforts to provide water through drilling of a borehole and rainwater harvesting have been tried and failed. The borehole construction was stopped, as it was believed to be draining water from the nearby Marsabit forest. A cemented tank that was put up by the County Government has remained dry as there is no rain. Rains in the area are only expected in October. The few tanks available donated by local NGOs have not been distributed as they are few and there is fear of rivalry in the community and towards the NGO in case a manyatta is left out during the distribution.

\section{Results and Discussion}

At the initiation of the study, 37 children were underweight and sick. They qualified to receive nutritional food supplements. Even with the supplements, the children did not improve nutritionally because of constant diarrhea, caused by drinking contaminated water (Table 1).

\begin{tabular}{|c|c|c|c|c|c|c|}
\hline \multirow[t]{3}{*}{ Name } & \multicolumn{6}{|c|}{$\begin{array}{l}\text { MUAC measurement in children on a Plumpy'Nut diet in a three month period } \\
\text { before introduction of the water backpack }\end{array}$} \\
\hline & \multicolumn{2}{|c|}{ June } & \multicolumn{2}{|c|}{ July } & \multicolumn{2}{|c|}{ August } \\
\hline & Week 2 & Week 4 & Week 6 & Week 8 & Week 10 & Week 12 \\
\hline Child 1 & 10.3 & 10.4 & 10.6 & 10.7 & 10.9 & 11.2 \\
\hline Child 2 & 10.6 & 10.7 & 10.7 & 10.8 & 10.9 & 10.9 \\
\hline Child 3 & 10.2 & 10.3 & 10.5 & 10.7 & 10.9 & 11.1 \\
\hline Child 4 & 10.3 & 10.4 & 10.6 & 10.7 & 10.9 & 11.1 \\
\hline Child 5 & 10.4 & 10.6 & 10.7 & 10.9 & 11.2 & 11.5 \\
\hline Child 6 & 10.2 & 10.3 & 10.5 & 10.6 & 10.7 & 10.9 \\
\hline Child 7 & 10.1 & 10.2 & 10.3 & 10.5 & 10.6 & 10.8 \\
\hline Child 8 & 10.2 & 10.3 & 10.5 & 10.6 & 10.8 & 11 \\
\hline Child 9 & 10.5 & 10.6 & 10.7 & 10.8 & 10.9 & 11.1 \\
\hline Child 10 & 10.2 & 10.3 & 10.3 & 10.5 & 10.6 & 10.7 \\
\hline Child 11 & 10.4 & 10.4 & 10.5 & 10.6 & 10.8 & 11 \\
\hline Child 12 & 10.3 & 10.3 & 10.4 & 10.6 & 10.6 & 10.7 \\
\hline Child 13 & 10.3 & 10.4 & 10.5 & 10.6 & 10.6 & 10.7 \\
\hline Child 14 & 10.5 & 10.5 & 10.6 & 10.7 & 10.8 & 10.9 \\
\hline Child 15 & 10.3 & 10.4 & 10.5 & 10.6 & 10.7 & 10.8 \\
\hline Child 16 & 10.2 & 10.3 & 10.4 & 10.4 & 10.5 & 10.6 \\
\hline Child 17 & 10.5 & 10.5 & 10.6 & 10.7 & 10.9 & 11 \\
\hline Child 18 & 10.3 & 10.4 & 10.4 & 10.5 & 10.6 & 10.8 \\
\hline Child 19 & 10.5 & 10.6 & 10.7 & 10.8 & 10.8 & 11 \\
\hline Child 20 & 10.2 & 10.3 & 10.5 & 10.6 & 10.7 & 10.8 \\
\hline Child 21 & 10.3 & 10.3 & 10.4 & 10.6 & 10.6 & 10.7 \\
\hline
\end{tabular}




\begin{tabular}{|l|l|l|l|l|l|l|} 
Child 22 & 10.2 & 10.3 & 10.4 & 10.5 & 10.6 & 10.7 \\
\hline Child 23 & 10.5 & 10.6 & 10.7 & 10.8 & 10.8 & 11 \\
\hline Child 24 & 10.3 & 10.4 & 10.6 & 10.7 & 10.9 & 11.1 \\
\hline Child 25 & 10.1 & 10.2 & 10.3 & 10.5 & 10.6 & 10.8 \\
\hline Child 26 & 10.2 & 10.3 & 10.5 & 10.7 & 10.8 & 10.9 \\
\hline Child 27 & 10.4 & 10.5 & 10.6 & 10.8 & 10.9 & 11 \\
\hline Child 28 & 11.2 & 11.2 & 11.4 & 11.5 & 11.6 & 11.6 \\
\hline Child 29 & 11.4 & 11.5 & 11.5 & 11.6 & 11.7 & 11.7 \\
\hline Child 30 & 11.3 & 11.6 & 11.7 & 11.9 & 12.1 & 12.1 \\
\hline Child 31 & 11.5 & 11.7 & 11.9 & 11.7 & 11.9 & 12 \\
\hline Child 32 & 11.4 & 11.6 & 11.5 & 11.7 & 11.7 & 11.7 \\
\hline Child 33 & 11.2 & 11.3 & 11.3 & 11.4 & 11.4 & 11.5 \\
\hline Child 34 & 11.4 & 11.6 & 11.6 & 11.7 & 11.9 & 11.9 \\
\hline Child 35 & 11.3 & 11.3 & 11.3 & 11.4 & 11.5 & 11.5 \\
\hline Child 36 & 11.3 & 11.5 & 11.7 & 11.7 & 11.8 & 11.9 \\
\hline Child 37 & 11.2 & 11.4 & 11.8 & 11.8 & 11.9 & 12.3 \\
\hline
\end{tabular}

Table 1: MUAC measurements for thirty seven (37) children on a Plumpy'Nut diet before safe water intervention.

The data shows marginal or no improvement in the health status of the children the same children were observed once they had safe water to drink from the water backpacks. Observations and measurements indicated substantial improvement (Table 2).

\begin{tabular}{|c|c|c|c|c|c|c|}
\hline \multirow[t]{3}{*}{ Name } & \multicolumn{6}{|c|}{$\begin{array}{l}\text { MUAC measurement in the three month intervention period (after introduction of } \\
\text { the water backpack) }\end{array}$} \\
\hline & \multicolumn{2}{|c|}{ September } & \multicolumn{2}{|l|}{ October } & \multicolumn{2}{|c|}{ November } \\
\hline & Week 2 & Week 4 & Week 6 & Week 8 & Week 10 & Week 12 \\
\hline Child 1 & 11.2 & 11.5 & 11.8 & 12.2 & 12.3 & 12.4 \\
\hline Child 2 & 11.4 & 11.6 & 11.8 & 12.1 & 12.4 & 12.4 \\
\hline Child 3 & 11.4 & 11.5 & 11.8 & 12.1 & 12.2 & 12.3 \\
\hline Child 4 & 11.3 & 11.5 & 11.7 & 11.9 & 12 & 12.4 \\
\hline Child 5 & 11.6 & 11.8 & 12 & 12.2 & 12.4 & 12.4 \\
\hline Child 6 & 11.3 & 11.5 & 11.8 & 12.1 & 12.2 & 12.3 \\
\hline Child 7 & 11.1 & 11.3 & 11.5 & 11.8 & 12.1 & 12.4 \\
\hline Child 8 & 11.6 & 11.8 & 12.3 & 12.5 & 12.7 & 12.9 \\
\hline Child 9 & 11.3 & 11.5 & 11.7 & 11.9 & 12.2 & 12.4 \\
\hline Child 10 & 11.2 & 11.4 & 11.5 & 11.7 & 11.9 & 12.3 \\
\hline Child 11 & 11 & 11.2 & 11.3 & 11.5 & 11.7 & 12 \\
\hline Child 12 & 11.7 & 12.1 & 12.4 & 12.6 & 12.8 & 13 \\
\hline Child 13 & 11.1 & 11.2 & 11.4 & 11.7 & 11.9 & 12.2 \\
\hline Child 14 & 12.1 & 12.3 & 12.5 & 12.7 & 12.9 & 13.1 \\
\hline
\end{tabular}




\begin{tabular}{|l|l|l|l|l|l|l|} 
Child 15 & 10.9 & 11.2 & 11.3 & 11.5 & 11.7 & 11.9 \\
\hline Child 16 & 11.1 & 11.2 & 11.4 & 11.6 & 11.8 & 12.1 \\
\hline Child 17 & 11.2 & 11.3 & 11.4 & 11.6 & 11.8 & 12 \\
\hline Child 18 & 11.1 & 11.3 & 11.5 & 11.7 & 11.9 & 12.2 \\
\hline Child 19 & 12 & 12.3 & 12.5 & 12.7 & 12.9 & 13.2 \\
\hline Child 20 & 11.7 & 11.8 & 12.1 & 12.4 & 12.6 & 12.8 \\
\hline Child 21 & 10.9 & 11.2 & 11.4 & 11.5 & 11.7 & 11.9 \\
\hline Child 22 & 11.2 & 11.3 & 11.5 & 11.7 & 11.7 & 11.9 \\
\hline Child 23 & 11.1 & 11.3 & 11.4 & 11.6 & 11.8 & 12 \\
\hline Child 24 & 11.2 & 11.3 & 11.4 & 11.6 & 11.8 & 12.1 \\
\hline Child 25 & 11.1 & 11.3 & 11.4 & 11.6 & 11.8 & 12 \\
\hline Child 26 & 11.7 & 11.8 & 12.1 & 12.3 & 12.5 & 12.8 \\
\hline Child 27 & 10.9 & 11.2 & 11.4 & 11.7 & 11.9 & 12.1 \\
\hline Child 28 & 10.9 & 11.2 & 11.5 & 11.7 & 11.9 & 12.1 \\
\hline Child 29 & 11.3 & 11.4 & 11.6 & 11.8 & 12.1 & 12.3 \\
\hline Child 30 & 11.9 & 12.2 & 12.4 & 12.6 & 12.8 & 13.1 \\
\hline Child 31 & 11.3 & 11.5 & 11.6 & 11.9 & 12.1 & 12.3 \\
\hline Child 32 & 11.1 & 11.3 & 11.6 & 11.8 & 12 & 12.3 \\
\hline Child 33 & 11.5 & 11.7 & 11.8 & 12 & 12.4 & 12.7 \\
\hline Child 34 & 11.2 & 11.4 & 11.6 & 11.9 & 12.2 & 12.4 \\
\hline Child 35 & 11.2 & 11.4 & 11.7 & 11.9 & 12.1 & 12.4 \\
\hline Child 36 & 11.9 & 12.1 & 12.4 & 12.6 & 12.8 & 12.9 \\
\hline Child 37 & 12.3 & 12.5 & 12.7 & 12.9 & 13.2 & 13.4 \\
\hline & & & & & & \\
\hline
\end{tabular}

Table 2: MUAC measurements for thirty seven (37) children on the Plumpy'Nut diet and receiving safe water from the water backpack.

Of the 37 children, ten (10) children i.e. children 8, 12, 14, 19, 20, 26, 30, 33, 36, and 37 registered remarkable improvement in MUAC measurements $(\geq 12.5)$ and general health. These children were removed from the Plumpy'Nut program. In order to confirm their full recovery outside the food supplements, they were as a standard practise followed for a month. Table 3 shows the MUAC measurements post Plumpy'Nut program.

\begin{tabular}{|l|l|l|}
\hline Identity & December \\
\hline & Week 2 & Week 4 \\
\hline Child 8 & 12.8 & 12.7 \\
\hline Child 12 & 12.8 & 12.8 \\
\hline Child 14 & 12.9 & 12.9 \\
\hline Child 19 & 13 & 12.8 \\
\hline Child 20 & 12.7 & 12.7 \\
\hline Child 26 & 12.8 & 12.6 \\
\hline Child 30 & 12.7 & 12.6 \\
\hline Child 33 & 12.5 & 12.5 \\
\hline
\end{tabular}




\begin{tabular}{|l|l|l|} 
Child 36 & 12.8 & 12.5 \\
\hline Child 37 & 13 & 12.7 \\
\hline
\end{tabular}

Table 3: Children MUAC measurements when off plumpy nut but on safe water.

A random MUAC measurements long after the program has indicated that the children have remained health since their families have embraced use of safe water from the water backpacks (Table 4).

\begin{tabular}{|l|l|l|}
\hline Name & Age & $\begin{array}{l}\text { MUAC after leaving } \\
\text { the nutritional } \\
\text { supplement program }\end{array}$ \\
\hline Child 8 & 8months & 12.9 \\
\hline Child 12 & 1 year & 13 \\
\hline Child 14 & 1 year & 13.1 \\
\hline Child 19 & 10months & 13.2 \\
\hline Child 20 & 8months & 12.8 \\
\hline Child 26 & 10months & 12.8 \\
\hline Child 30 & 1 year & 13.1 \\
\hline Child 33 & 1 year & 12.7 \\
\hline Child 36 & 8months & 12.9 \\
\hline Child 37 & 1 year & 13.4 \\
\hline
\end{tabular}

Table 4: Children who are no longer in the Government feeding program thanks to safe water from the water backpack after three months of intervention.

MUAC measurement for children on plumpy nut who visited Parkishon dispensary but did not receive safe water from the water backpack during the intervention period were also recorded (Table 5).

\begin{tabular}{|l|l|l|l|l|l|l|}
\hline \multicolumn{4}{|l}{} & \multicolumn{3}{l}{ MUAC measurement in the three month intervention period } \\
\hline Identity & September & \multicolumn{2}{|c|}{ October } & \multicolumn{2}{c|}{ November } \\
\hline & Week 2 & Week 4 & Week 6 & Week 8 & Week 10 & Week 12 \\
\hline Child 38 & 11.3 & 11.3 & 11.4 & 11.5 & 11.5 & 11.5 \\
\hline Child 39 & 11.5 & 11.5 & 11.6 & 11.6 & 11.6 & 11.7 \\
\hline Child 40 & 11.4 & 11.5 & 11.6 & 11.6 & 11.7 & 11.8 \\
\hline Child 41 & 11.2 & 11.2 & 11.3 & 11.4 & 11.4 & 11.6 \\
\hline
\end{tabular}

Table 5: MUAC measurements for children on the Plumpy'Nut diet using water from the normal sources.

The children under this category are still receiving the nutritional supplement since they are yet to recover fully. These results fully demonstrate the importance of a clean source of safe water when managing malnutrition since the results show that nutritional supplements alone are not enough (Figure 1). 


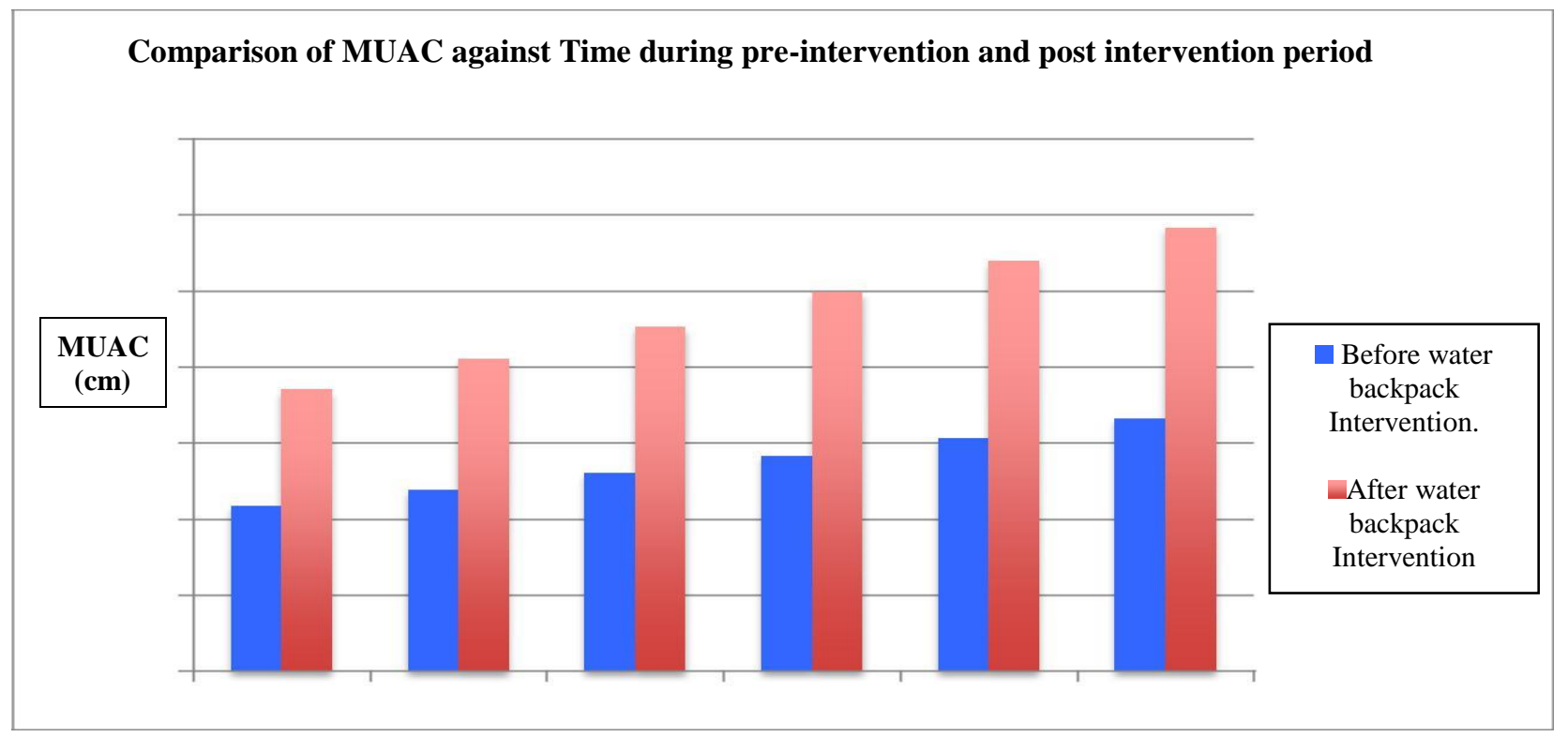

Figure 1: Summary of the average MUAC measurements between children using safe (water backpack) water and contaminated water.
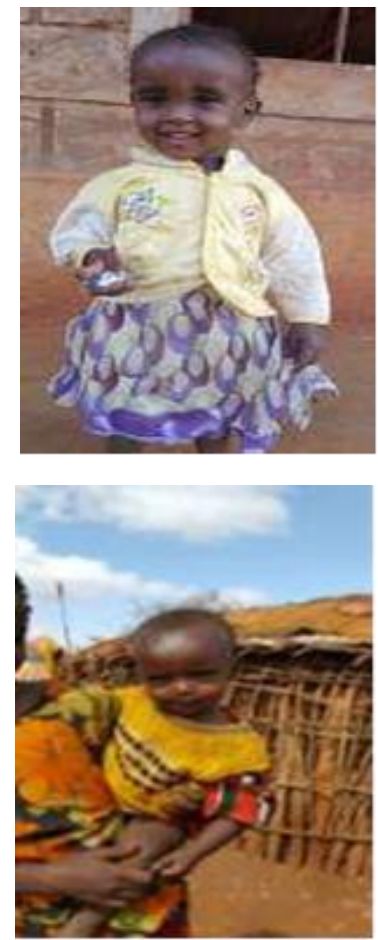

Fracases Naeda, Age: 8months, Arm Circumference increased from $11.4 \mathrm{~cm}$ to $12.1 \mathrm{~cm}$
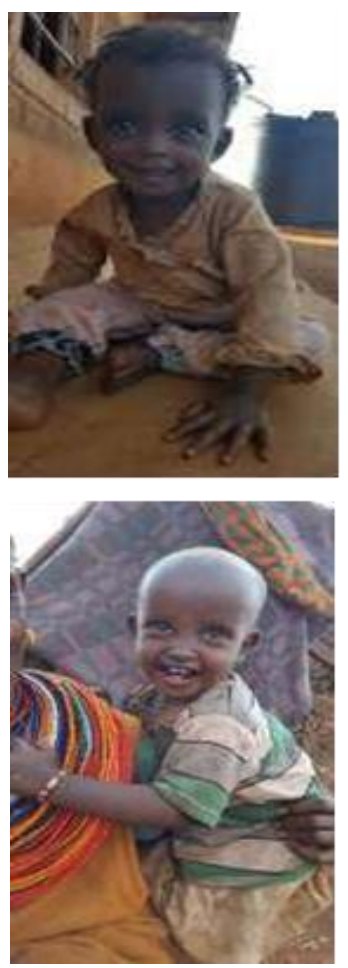

Miaka Mpiya, Age: 3 years, Arm Circumference increased from $11.5 \mathrm{~cm}$ to $12.4 \mathrm{~cm}$

Image 2: Selected Photos* of the Beneficiaries of the Safe Water Campaign. *Photos used with permission from the guardians. 


\section{Conclusion}

The residents of Parkishon now understand how to prevent water borne illnesses and have no re-occurrence of waterborne illnesses since they began using the packs. Once the children had safe water to drink from the water backpacks, there has been tremendous improvement in their health, as $27 \%$ of the children who were once malnourished are no longer in need of nutritional supplements. The rest are showing great improvement in health.

This project is an opportunity to improve healthcare of the people of Parkishon, in Marsabit, and provides evidencebased proof for the strong correlation between the quality of water and improvement of health for children enrolled in a nutritional supplement programme. The information obtained is useful when upscaling such interventions in other parts of the country.

\section{Acknowledgement}

The authors wish to acknowledge support and contribution of the County Government of Marsabit, Community Health Workers in Parkishon, and the entire medical team at Parkishon dispensary.

\section{References}

1. Prüss-Üstün A., Bos, R., Gore, F. \& Bartram, J. 2008. Safer water, better health: costs, benefits and sustainability of interventions to protect and promote health.[PDF - 60 pages] World Health Organization, Geneva.

2. Kenya National Bureau of Statistics (2013). Economic Survey. KNBS, Nairobi.

3. United Nations Millennium Project. Health, Dignity, and Development.

Citation: Peter G. Kirira, Connie Cheren, Linus Ndegwa, Ashley Waudo. Quality of Water and the Recovery Time of Malnourished Children Enrolled In a Nutritional Feeding Programme: Lessons from Parkishon Region, Marsabit County, Kenya. Archives of Clinical and Medical Case Reports 2 (2018): 113-123.

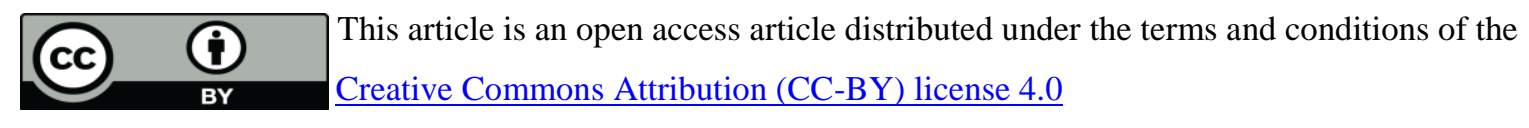

